\title{
The effect of maternal obesity on the success of labor induction with a cervical ripening double-balloon catheter and on pain perception during catheter insertion
}

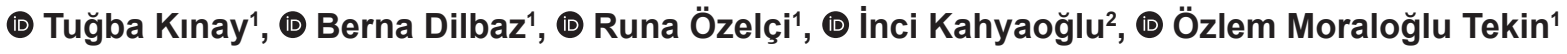 \\ 1 University of Health Sciences Turkey, Etlik Zubeyde Hanim Women's Health Training and Research Hospital, Clinic of Obstetrics \\ and Gynecology, Ankara, Turkey
}

2University of Health Sciences Turkey, Zekai Tahir Burak Women's Health Training and Research Hospital, Clinic of Obstetrics and Gynecology, Ankara, Turkey

Date submitted:

25.05.2019

Date accepted:

12.11.2019

Online publication date:

15.03.2020

\section{Corresponding Author:}

Tuğba Kınay MD, University of Health Sciences Turkey, Etlik Zübeyde Hanım Women's Health Training and Research Hospital, Clinic of Obstetrics and Gynecology, Ankara, Turkey

tkinay@hotmail.com

ORCID:

orcid.org/0000-0001-5340-1025

Presented in: The abstract of the manuscript represented as a poster at the 3. International Pregnancy, Birth and Puerperium Congress, on February 14-17, 2019, Bolu, Turkey.

Keywords: Double-balloon catheter, labor induction, multiparity, obesity, pain

\begin{abstract}
Aim: To evaluate the effect of maternal body mass index (BMI) on the success of labor induction with a cervical ripening double-balloon catheter and maternal pain perception during the catheter insertion process.

Methods: This observational study included 103 women with singleton pregnancies, who underwent labor induction with a double-balloon catheter at $\geq 39$ weeks of gestation for obstetric indications. The study population was divided into two groups according to the BMI (group $1<30 \mathrm{~kg} / \mathrm{m}^{2}$ and group $2 \geq 30 \mathrm{~kg} / \mathrm{m}^{2}$ ). The two groups were compared in terms of their clinical characteristics, labor outcomes, cesarean delivery rate, delivery rate within 24 hours of insertion, and maternal pain perception during catheter insertion.
\end{abstract}

Results: The two BMI groups showed no significant differences in the cesarean delivery rate (31.5\% vs. $42.9 \%)$, the delivery rate within 24 hours of labor induction ( $85.2 \%$ vs. $81.6 \%)$, and Visual Analog Scale (VAS) score (4.8 \pm 2.9 vs. $4.6 \pm 2.5)(p>0.05)$. The cesarean delivery rate was $19.6 \%$ in multiparous women and $57.4 \%$ in nulliparous women $(p<0.001)$. The median Bishop scores upon admission and at the time of balloon expulsion were higher in women who delivered vaginally than in those who underwent cesarean sections [4 (1-5) vs. 2 (1-5) and 7 (4$11)$ vs. 6 (2-8), respectively, $p<0.001]$. The VAS scores recorded during double-balloon catheter insertion ( $4.8 \pm 2.9$ vs. $4.6 \pm 2, p=0.772)$ were also similar in both groups.

Conclusion: Maternal BMI did not affect the success of labor induction with a cervical ripening double-balloon catheter. Parity and Bishop scores were the factors influencing labor induction success.

\section{Introduction}

Over the last few decades, obesity [body mass Index (BMI) $\geq 30 \mathrm{~kg} / \mathrm{m}^{2}$ ] has become one of the major health problems worldwide. Globally, the prevalence of overweight and obese adult women has increased from $29.8 \%$ in 1980 to $38.0 \%$ in 2013 (1). Obesity, which has also become common in women of reproductive age, increases the occurrence of obstetric complications, such as gestational diabetes mellitus, hypertension, fetal macrosomia, prolonged delivery time, and dystocia at birth (2-6). Obese women are also at increased risk for labor induction and their cesarean section rates are increased (7-9). 
Labor induction with mechanical or pharmacological agents is now a commonly performed obstetrical intervention for various indications, such as prolonged gestation, fetal growth restriction, and oligohydramnios. Although some factors, such as the Bishop score and cervical length, can affect the success of labor induction, the factors that predict its success are not yet clear $(10,11)$. The cesarean delivery rate is approximately $17 \%$ in women who undergo labor induction (12).

The efficacy of mechanical devices is comparable to that of pharmacological agents, as different mechanical devices have similar or higher vaginal delivery rates $(13,14)$. One of the mechanical devices, the double-balloon catheter, enables cervical ripening by stimulating endogenous prostaglandin release (15). Balloon induction has a lower incidence of fetal tachysystole, but a higher need for oxytocin augmentation when compared to prostaglandin treatments $(15,16)$. One disadvantage of balloon induction is a pain sensation during insertion.

This observational study was conducted to determine the impact of maternal BMI on the success of labor induction with a cervical ripening double-balloon catheter and to evaluate pain perception during catheter insertion. The cesarean section rate, delivery rate within 24 hours of labor induction, and Visual Analog Scale (VAS) pain score during double-balloon catheter insertion were compared between women with a BMI at or above $30 \mathrm{~kg} /$ $\mathrm{m}^{2}$ and women with a $\mathrm{BMl}<30 \mathrm{~kg} / \mathrm{m}^{2}$.

\section{Methods}

The participants in this observational study were women with a single fetus in vertex presentation and a Bishop score of less than six, who underwent labor induction with a cervical ripening double-balloon catheter at 39 weeks' gestation or beyond at tertiary care center, between May 1 and November 1, 2018. The study protocol was approved by the Ethical Committee of the University of Health Sciences Turkey, Etlik Zubeyde Hanim Women's Health Training and Research Hospital (2018/8), and complied with the Helsinki Declaration, including current revisions. Signed written informed consent was obtained from all the participants who volunteered to participate in the study. Exclusion criteria included age under 18 years, multiple pregnancies, breech presentation, transverse position, prior cesarean delivery or uterine surgery, a Bishop score greater than or equal to six at admission, diabetes mellitus, hypertension, cardiac disease, premature rupture of membranes, chorioamnionitis, fetal demise, polyhydramnios, placenta previa, and a gestational age $<39$ weeks.

Prior to the cervical ripening double-balloon insertion, the gestational age of the participants was evaluated according to the last menstrual period and/or ultrasonographic findings in the first and early second trimester. Upon admission, a pelvic examination was performed to evaluate the fetal presentation and the maternal pelvic structure and to determine the baseline Bishop score. A reassuring fetal status was confirmed by a biophysical profile, non-stress test, and/or oxytocin challenge test. A double-balloon catheter was inserted into the cervical canal according to the previously described technique $(17,18)$. The fetal heart rate was continuously monitored externally during induction. The double-balloon catheter was spontaneously expelled or it was removed upon completion of the 12-hour period or upon observation of a non-reassuring fetal heart rate. After the balloon removal, the Bishop score was re-evaluated via cervical examination, and oxytocin augmentation was performed in women who were not in an active phase of labor (defined as a period of labor from $5 \mathrm{~cm}$ of cervical dilatation with regular uterine contractions to delivery) (19). Oxytocin augmentation was also performed in cases of prolonged labor or labor arrest with uterine contractions of less than 200 Montevideo units. Unchanged cervical dilatation and effacement for four hours or a second stage of labor longer than two hours were defined as failures to progress.

The data collected included maternal age, BMI, gravidity, parity, gestational age, previous obstetrical history of multiparous women, the amniotic fluid index, indications for labor induction, Bishop scores upon admission, time to expulsion of the balloon, the duration of labor after induction, the need for oxytocin augmentation, the mode of delivery, indications for a cesarean section, and newborn birthweight, head circumference, and height. An amniotic fluid index of less than $5 \mathrm{~cm}$ was considered to indicate oligohydramnios (20). A gestational age greater than 41 weeks was defined as prolonged pregnancy. Pain perception during balloon insertion was evaluated using a 10-cm VAS score, as described previously (21).

The study population was divided into two groups according to BMI: group $1<30 \mathrm{~kg} / \mathrm{m}^{2}$ and group $2 \geq 30 \mathrm{~kg} / \mathrm{m}^{2}$. The clinical characteristics, labor outcomes, cesarean delivery rate, delivery rate within a 24-hour period of labor induction, and VAS scores for patient's pain perception during double-balloon catheter insertion were compared for the two groups. Other factors associated with labor induction success and maternal pain perception were also evaluated.

\section{Statistical Analysis}

Statistical analysis was performed with SPSS version 17 (SPSS, Chicago, Illinois, USA). The normality for continuous variables was analyzed using the Kolmogorov-Smirnov test. The descriptive statistics presented were the mean value and standard deviation or median (minimum-maximum) for the continuous variables and the numbers and percentages for the categorical variables. Differences in normally distributed continuous variables were analyzed using an independent sample t-test and variables without normal distribution were analyzed using the Mann-Whitney $U$ test. Differences in 
categorical variables were examined with the chi-square test. A $p$ value of less than 0.05 was considered to be statistically significant.

\section{Results}

During the study period, 103 women who were eligible for the study underwent labor induction with a cervical ripening doubleballoon catheter. Labor was induced for prolonged pregnancy in 49 women (47.6\%), for oligohydramnios in 22 women $(21.4 \%)$, and for non-reassuring fetal status in 32 women (31.1\%). BMI was $<30 \mathrm{~kg} / \mathrm{m}^{2}$ in 54 (52.4\%) women (group 1), whereas, in the remaining 49 women (group 2), $32(31.1 \%$ ) had a BMI of 30 $34.9 \mathrm{~kg} / \mathrm{m}^{2}$ and 17 women had a BMI $\geq 35 \mathrm{~kg} / \mathrm{m}^{2}$.

The clinical characteristics and labor outcomes of the two groups are shown in Table 1 . The median maternal age was lower [24 (18-40) years vs. $27(18-43)$ years, $p=0.023$ ] and gestational age was higher [41 (39-42) weeks vs. 40 (39-41) weeks, $p=0.042$ ] in group 1 . No significant differences were detected for gravidity, parity, incidence of oligohydramnios, and Bishop scores upon admission and at the time of balloon expulsion between the groups $(p>0.05)$. No association was found between the BMI and labor outcomes. The duration of labor (17.4 $\pm 5.2 \mathrm{~h}$ in group $1,17.5 \pm 6.1 \mathrm{~h}$ in group $2, \mathrm{p}=0.960)$, cesarean section rate $(31.5 \%$ in group $1,42.9 \%$ in group 2 , $\mathrm{p}=0.232$ ), and delivery rate within 24 hours of balloon insertion (85.2\% in group $1,81.6 \%$ in group $2, p=0.628$ ) did not differ between the two groups. No operative deliveries were required in either of the groups. The VAS scores recorded during doubleballoon catheter insertion (4.8 \pm 2.9 in group $1,4.6 \pm 2.5$ in group $2, p=0.772$ ) were also similar in both groups.

The overall cesarean delivery rate was $36.9 \%$ in the study population. The indications for cesarean delivery were fetal

\begin{tabular}{|c|c|c|c|}
\hline Characteristics & $\begin{array}{l}\text { Group } 1 \\
\text { BMI <30 kg/m² } \\
(\mathrm{n}=54)\end{array}$ & $\begin{array}{l}\text { Group } 2 \\
\text { BMI } \geq 30 \mathrm{~kg} / \mathrm{m}^{2} \\
(\mathrm{n}=49)\end{array}$ & $p$ value \\
\hline \multicolumn{4}{|l|}{ Clinical characteristics } \\
\hline Maternal age (y) & $24(18-40)$ & $27(18-43)$ & $0.023^{* *}$ \\
\hline Gravidity & $2(1-6)$ & $2(1-7)$ & $0.119^{* *}$ \\
\hline Parity & $1(0-3)$ & $1(0-3)$ & $0.116^{* *}$ \\
\hline Multiparous women & $27(50.0 \%)$ & $29(59.2 \%)$ & $0.350^{* \star \star}$ \\
\hline Gestational age (w) & $41(39-42)$ & $40(39-41)$ & $0.042^{* *}$ \\
\hline Oligohydramnios & $13(24.1 \%)$ & $10(20.4 \%)$ & $0.655^{* * *}$ \\
\hline \multicolumn{4}{|l|}{ Labor characteristics } \\
\hline Bishop score upon admission & $4(2-5)$ & $3(1-5)$ & $0.077^{* *}$ \\
\hline Bishop score upon balloon expulsion & $7(4-11)$ & $7(2-10)$ & $0.470^{* *}$ \\
\hline Spontaneous balloon expulsion rate & $27(50.0 \%)$ & $28(57.1 \%)$ & $0.468^{* \star *}$ \\
\hline Balloon insertion to expulsion time $(\mathrm{h})$ & $12(1-12)$ & $10(1-12)$ & $0.175^{* *}$ \\
\hline Balloon insertion to active labor onset time (h) & $12.6 \pm 4.1$ & $12.4 \pm 5.8$ & $0.802^{*}$ \\
\hline Balloon insertion to delivery time $(\mathrm{h})$ & $17.4 \pm 5.2$ & $17.5 \pm 6.1$ & $0.960^{*}$ \\
\hline Balloon expulsion to delivery time $(\mathrm{h})$ & $7.9 \pm 4.6$ & $9.3 \pm 4.8$ & $0.389^{*}$ \\
\hline Oxytocin need & $32(59.3 \%)$ & $30(61.2 \%)$ & $0.839^{\star \star \star}$ \\
\hline Cesarean delivery & $17(31.5 \%)$ & $21(42.9 \%)$ & $0.232^{\star \star \star}$ \\
\hline Delivery within $24 \mathrm{~h}$ & $46(85.2 \%)$ & $40(81.6 \%)$ & $0.628^{\star \star \star}$ \\
\hline VAS score & $4.8 \pm 2.9$ & $4.6 \pm 2.5$ & $0.772^{*}$ \\
\hline \multicolumn{4}{|l|}{ Newborn characteristics } \\
\hline Birthweight (gr) & $3406.9 \pm 422.0$ & $3361.7 \pm 325.5$ & $0.331^{*}$ \\
\hline Head circumference $(\mathrm{cm})$ & $34.9 \pm 1.4$ & $34.5 \pm 1.1$ & $0.078^{*}$ \\
\hline Height $(\mathrm{cm})$ & $51(45-56)$ & $51(46-54)$ & $0.449^{* *}$ \\
\hline $\begin{array}{l}\mathrm{p}>0.05 \\
\text { Data are the mean } \pm \text { standard deviation, median (minimum-r } \\
{ }^{*} \text { The t-test was used. } \\
{ }^{* *} \text { The Mann-Whitney U test was used. } \\
{ }^{* * *} \text { The Chi-square test was used. } \\
\text { VAS: Visual Analog Scale, BMI: Body Mass Index }\end{array}$ & ber (\%). & & \\
\hline
\end{tabular}


distress in 22 women (21.4\%), failure to progress in 15 women $(14.6 \%)$, and a prolapsed umbilical cord in one woman (2.6\%).

The characteristics affecting the success of induction and duration of labor are shown in Table 2. Significant differences were noted for gravidity $(p<0.001)$, parity $(p=0.001)$, the Bishop score upon admission $(p<0.001)$, and the time to balloon expulsion $(p<0.001)$ between the women with vaginal and with cesarean deliveries. The median Bishop scores at admission and the time of balloon expulsion were 4 (minimum 1-maximum 5) and 7 (minimum 4-maximum 11) in women with vaginal deliveries, and 2 (minimum 1-maximum 5) and 6 (minimum 2-maximum 8) in women who had cesarean deliveries, respectively $(p<0.001)$.
Compared to the cesarean delivery group, balloon insertion to expulsion time $(p=0.011)$, balloon insertion to delivery time $(p<0.001)$, and balloon expulsion to delivery time $(p=0.025)$ were shorter in the vaginal delivery group. Spontaneous balloon expulsion and the rates of need for oxytocin augmentation did not differ between the women with vaginal and cesarean deliveries. Similar results were observed in women who delivered within 24 hours of labor induction. Gravidity $(p=0.011)$, parity $(p=0.009)$ and the Bishop scores upon admission $(p<0.001)$ and at the time of balloon expulsion $(p<0.001)$ were higher; balloon insertion to expulsion time $(p=0.001)$, balloon insertion to delivery time $(p<0.001)$, and balloon expulsion to delivery time $(p<0.001)$

Table 2. Clinical characteristics and labor outcomes according to the delivery mode and labor time

\begin{tabular}{|c|c|c|c|c|c|c|}
\hline \multirow[t]{2}{*}{ Characteristics } & \multicolumn{3}{|l|}{ Delivery mode } & \multicolumn{3}{|c|}{ Delivery within 24 hours } \\
\hline & $\begin{array}{l}\text { Vaginal } \\
\text { delivery } \\
n=65\end{array}$ & $\begin{array}{l}\text { Cesarean } \\
\text { delivery } \\
n=38\end{array}$ & $p$ value & $\begin{array}{l}(+) \\
n=86\end{array}$ & $\begin{array}{l}(-) \\
n=17\end{array}$ & $\mathrm{p}$ value \\
\hline \multicolumn{7}{|l|}{ Clinical characteristics } \\
\hline Maternal age $(\mathrm{y})$ & $25(18-40)$ & $26(18-43)$ & $0.598^{*}$ & $26(18-43)$ & $25(18-38)$ & $0.203^{* *}$ \\
\hline BMI $\left(\mathrm{kg} / \mathrm{m}^{2}\right)$ & $30.2 \pm 4.6$ & $31.0 \pm 5.7$ & $0.451^{*}$ & $30.6 \pm 4.9$ & $30.3 \pm 5.5$ & $0.857^{*}$ \\
\hline Gravidity & $2(1-7)$ & $1(1-5)$ & $<0.001^{* *}$ & $2(1-7)$ & $1(1-3)$ & $0.011^{* *}$ \\
\hline Parity & $1(0-3)$ & $0(0-3)$ & $0.001^{* *}$ & $1(0-3)$ & $0(0-2)$ & $0.009^{* *}$ \\
\hline Nulliparous & $20(42.6 \%)$ & $27(57.4 \%)$ & $<0.001^{* * *}$ & $34(27.7 \%)$ & $13(72.3 \%)$ & $0.005^{* * *}$ \\
\hline Multiparous & $45(80.4 \%)$ & $11(19.6 \%)$ & $<0.001^{* * *}$ & $52(7.1 \%)$ & $4(92.9 \%)$ & $0.005^{* * *}$ \\
\hline Gestational age (w) & $40(39-42)$ & $41(39-42)$ & $0.163^{* *}$ & $40(39-42)$ & $41(39-41)$ & $0.664^{* *}$ \\
\hline Oligohydramnios & $18(27.7 \%)$ & $5(13.2 \%)$ & $0.087^{* * *}$ & $19(22.1 \%)$ & $4(23.5 \%)$ & $0.897^{* * *}$ \\
\hline Interval between the births $(y)^{\dagger}$ & $5(1.5-16)$ & $6(2-17)$ & $0.385^{* *}$ & $5(1.5-17)$ & $8(7-16)$ & $0.059^{* *}$ \\
\hline History of prolonged pregnancy ${ }^{\dagger}$ & $10(25.6 \%)$ & $2(16.7 \%)$ & $0.522^{* * *}$ & $11(23.4 \%)$ & $1(25 \%)$ & $0.671^{* * *}$ \\
\hline \multicolumn{7}{|l|}{ Labor characteristics } \\
\hline Bishop score upon admission & $4(1-5)$ & $2(1-5)$ & $<0.001^{*}$ & $3(1-5)$ & $2(1-4)$ & $<0.001^{*}$ \\
\hline Bishop score upon balloon expulsion & $7(4-11)$ & $6(2-8)$ & $<0.001^{*}$ & $7(4-11)$ & $4(2-8)$ & $<0.001^{*}$ \\
\hline Spontaneous balloon expulsion rate & $39(60.0 \%)$ & $16(42.1 \%)$ & $0.079^{* * *}$ & $53(61.6 \%)$ & $2(11.8 \%)$ & $<0.001^{* * *}$ \\
\hline Balloon insertion to expulsion time $(\mathrm{h})$ & $9.5(1-12)$ & $12(5-12)$ & $0.011^{* *}$ & $10(1-12)$ & $12(7-12)$ & $0.001^{* *}$ \\
\hline $\begin{array}{l}\text { Balloon insertion to active labor onset } \\
\text { time (h) }\end{array}$ & $12.3 \pm 5.0$ & $14.2 \pm 4.9$ & $0.131^{*}$ & $12.0 \pm 4.5$ & $19.4 \pm 5.5$ & $<0.001^{*}$ \\
\hline Balloon insertion to delivery time $(\mathrm{h})$ & $16.7 \pm 5.5$ & $21.2 \pm 6.8$ & $<0.001^{*}$ & $16.4 \pm 4.7$ & $28.1 \pm 3.9$ & $<0.001^{*}$ \\
\hline Balloon expulsion to delivery time (h) & $8.1 \pm 4.6$ & $10.5 \pm 6.1$ & $0.025^{*}$ & $7.5 \pm 4.1$ & $16.6 \pm 4.0$ & $<0.001^{*}$ \\
\hline Oxytocin need & $37(56.9 \%)$ & $25(65.8 \%)$ & $0.375^{\star * *}$ & $46(53.5 \%)$ & $16(94.1 \%)$ & $0.002^{* * *}$ \\
\hline VAS score & $4.5 \pm 2.7$ & $4.8 \pm 3.3$ & $0.722^{*}$ & $4.6 \pm 2.8$ & $4.9 \pm 3.6$ & $0.715^{*}$ \\
\hline \multicolumn{7}{|l|}{ Newborn characteristics } \\
\hline Birthweight (gr) & $3389.2 \pm 388.6$ & $3331.3 \pm 326.3$ & $0.441^{*}$ & $3384.8 \pm 378.3$ & $3282.1 \pm 293.1$ & $0.293^{*}$ \\
\hline Head circumference $(\mathrm{cm})$ & $35(31-38)$ & $34.5(33-37)$ & $0.306^{* *}$ & $35(31-38)$ & $35(32-36)$ & $0.952^{\star *}$ \\
\hline Height $(\mathrm{cm})$ & $51(46-56)$ & $51(45-54)$ & $0.737^{* *}$ & $51(45-56)$ & $51(48-52)$ & $0.088^{* *}$ \\
\hline
\end{tabular}


were shorter in the women who delivered within 24 hours than in those who needed a longer time to deliver. In addition, the percentage of women with spontaneous balloon expulsion was higher $(p<0.001)$ while the interval from balloon insertion to active labor onset was shorter $(p<0.001)$, and the additional oxytocin augmentation rate was lower $(p=0.002)$ in the women who delivered within 24 hours.

In the total study population, the cesarean delivery rate was lower in multiparous women than in nulliparous women $(19.6 \%$ vs. $57.4 \%, p<0.001)$. When the two groups were analyzed separately, it was found that the cesarean delivery rates were $18.5 \%$ in multiparous women and $44.4 \%$ in nulliparous women in group $1(p<0.04)$, and $20.7 \%$ in multiparous women and $75 \%$ in nulliparous women in group $2(p<0.001)$.

No significant association was found between the BMI and pain perception during double- balloon insertion. The VAS scores were $4.8 \pm 2.9$ in group 1 and $4.6 \pm 2.5$ in group 2 $(p=0.772)$. The VAS scores also did not differ in women with Bishop scores of less than four or greater than four (4.7 \pm 3.2 vs. $4.7 \pm 2.7$, respectively, $p=0.974$ ) upon admission. However, the VAS scores were significantly lower in women over 30 years old (3.4 \pm 2.4 vs. $5.1 \pm 2.9, p=0.006)$ and in multiparous women (3.9 \pm 2.6 vs. $5.4 \pm 3.1, p=0.012)$.

\section{Discussion}

The results of the current study show that the success of labor induction with a cervical ripening double-balloon catheter was not affected by maternal obesity. The duration of labor, mode of delivery, and maternal pain perception did not differ between women with a BMl $<30 \mathrm{~kg} / \mathrm{m}^{2}$ and with a BMI $\geq 30 \mathrm{~kg} /$ $\mathrm{m}^{2}$.

Previous studies investigating the obstetrical outcomes of labor induction with prostaglandins identified BMI as an independent risk factor for cesarean delivery (22-25). A significantly increased cesarean delivery rate was reported with increasing maternal BMI in the secondary analysis of the Misoprostol Vaginal Insert Trial data (22). Analysis of the labor induction outcomes of 1,273 women with a parity $\leq 3$ with a singleton pregnancy at 36 weeks or more of gestation revealed a cesarean delivery rate of $21.3 \%$ in women with a BMI under 30 $\mathrm{kg} / \mathrm{m}^{2}, 29.8 \%$ in women with a BMI of $30-39.9 \mathrm{~kg} / \mathrm{m}^{2}$, and $36.5 \%$ in women with a BMI of $40 \mathrm{~kg} / \mathrm{m}^{2}$ or higher. The time to delivery was also longer in obese women than in women with a $\mathrm{BMI}<30$ $\mathrm{kg} / \mathrm{m}^{2}$ in this series. Another study also reported a significantly higher emergency cesarean rate among obese primigravida women who underwent labor induction with PGE2 (27.4\% vs. $29.5 \%)(23)$.

Conversely, maternal weight did not affect the success of mechanical devices for labor induction according to the previous studies. Mechanical methods eliminate the dilutional effect of the increased distribution volume of ripening agents in obese women. Anabusi et al. (26) analyzed the outcomes in women who underwent labor induction with a double-balloon or a Foley catheter and reported no difference in the duration of labor and the cesarean delivery rate with mechanical ripening devices between obese (25\%) and normal weight (17\%) women. We observed similar results in women who underwent labor induction with a double-balloon catheter only. The vaginal delivery rate and the delivery rate within 24 hours after the initiation of labor induction did not differ between the obese and normal weight women in our series. According to these results, the success of the double-balloon method seems to be independent of maternal weight. According to the results of our study, cervical ripening with a double-balloon catheter might be superior to pharmacological labor induction in obese women.

Similar to previous reports, an unfavorable Bishop score was identified as one of the predictors of the success of labor induction in our study group $(10,27)$. Lower Bishop scores at the time induction with a double balloon catheter and at the time catheter expulsion were observed in women who had cesarean deliveries.

The labor induction success rate was higher in multiparous women, as reported in previous studies $(12,24,27,28)$. Thorsell et al. (24) reported that the emergency cesarean section rate during labor induction with PGE2 vaginal gel or a transcervical catheter was $42 \%$ in nulliparous women and $14 \%$ in multiparous women at or after 41 weeks of gestation. Roos et al. (28) reported a five-fold increase in the cesarean section rate in post-term nulliparous women who underwent labor induction. Similar results have been reported in studies evaluating the success of labor induction with mechanical devices alone. Delaney et al. (27) reported a rate of $28 \%$ for cesarean section among nulliparous women and a $6 \%$ rate in multiparous women induced with a Foley catheter. However, in our study group, a prior history of prolonged pregnancy or duration between two consecutive births did not affect the success of labor induction.

One of the main disadvantages of mechanical methods compared to pharmacological agents is the pain sensation during catheter insertion. Advanced age and previous birth experiences may affect the intensity of the pain perception and improve pain tolerance during double-balloon catheter insertion. Our results indicated that younger and nulliparous women had a higher VAS pain scores, but maternal obesity had no effect on pain perception. The mean VAS score was 4.8 in lean women and 4.6 in women with a BMl of $30 \mathrm{~kg} / \mathrm{m}^{2}$ or more. Anabusi et al. (26) also reported similar pain perception rates between the obese and normal weight women with overall lower mean VAS scores; the mean VAS score was 3.5 in women with a BMI lower than $30 \mathrm{~kg} / \mathrm{m}^{2}$ and 3.2 in obese women. Ethnic and cultural differences between the study populations may be the cause of the differences in VAS score effects reported in the two studies. 
The main limitation of the present study was its observational design. The decision for labor induction or cesarean section was also made by different obstetricians. The other weakness of the study was that the study population included few morbidly obese women with BMI of $40 \mathrm{~kg} / \mathrm{m}^{2}$ or more. Larger studies are needed to allow the generalization of our results to morbidly obese women. However, the comparable clinical characteristics and the investigation of labor induction with a single mechanical method in the entire study population are the main strengths of this observational study. The effect of obesity on the success of labor induction was investigated without any confounding effects caused by different induction methods.

\section{Conclusion}

In conclusion, the current study demonstrated that maternal obesity had no influence on the outcome of labor induction with a cervical ripening double-balloon catheter. As reported in previous publications, parity and the Bishop score are the factors that affect labor induction success. A lower cesarean birth rate was observed in multiparous women and in women with a favorable Bishop score in this study. Therefore, a cervical ripening double-balloon catheter can be considered as one of the preferred options for labor induction in obese multiparous women.

\section{Ethics}

Ethics Committee Approval: The study protocol was approved by the Ethical Committee of the University of Health Sciences Turkey, Etlik Zubeyde Hanim Women's Health Training and Research Hospital (2018/8).

Informed Consent: Signed written informed consent was obtained from all the participants who volunteered to participate in the study.

Peer-review: Externally peer-reviewed.

\section{Authorship Contributions}

Concept: T.K., B.D., Design: T.K., B.D., Ö.M.T., Data Collection or Processing: T.K., R.Ö., İ.K., Analysis or Interpretation: B.D., R.Ö., I.K., Ö.M.T., Literature Search: R.Ö., İ.K., Writing: T.K.

Conflict of Interest: No conflict of interest was declared by the authors.

Financial Disclosure: The authors declared that this study received no financial support.

\section{References}

1. Ng M, Fleming $T$, Robinson M, et al. Global, regional, and national prevalence of overweight and obesity in children and adults during 1980-2013: a systematic analysis for the Global Burden of Disease Study 2013. Lancet. 2014;384:766-781.
2. Yu CK, Teoh TG, Robinson S. Obesity in pregnancy. BJOG. 2006;113:1117-1125.

3. Farah N, Maher N, Barry S, Kennelly M, Stuart B, Turner MJ. Maternal morbid obesity and obstetric outcomes. Obes Facts. 2009;2:352-354.

4. Vahratian A, Zhang J, Troendle JF, Savitz DA, Siega-Riz AM. Maternal prepregnancy overweight and obesity and the pattern of labor progression in term nulliparous women. Obstet Gynecol. 2004;104:943-951.

5. Nuthalapaty FS, Rouse DJ, Owen J. The association of maternal weight with cesarean risk, labor duration, and cervical dilation rate during labor induction. Obstet Gynecol. 2004;103:452-456.

6. Chu SY, Kim SY, Schmid CH, Dietz PM, Callaghan WM, Lau J, Curtis KM. Maternal obesity and risk of cesarean delivery: a meta-analysis. Obes Rev. 2007;8:385-394.

7. Wolfe KB, Rossi RA, Warshak CR. The effect of maternal obesity on the rate of failed induction of labor. Am J Obstet Gynecol. 2011;205:128.

8. Muto H, Ishii K, Nakano T, Hayashi S, Okamoto Y, Mitsuda $\mathrm{N}$. Rate of intrapartum cesarean section and related factors in older nulliparous women at term. J Obstet Gynaecol Res. 2018;44:217-222.

9. O'Dwyer V, Farah N, Fattah C, O'Connor N, Kennelly MM, Turner MJ. The risk of caesarean section in obese women analysed by parity. Eur J Obstet Gynecol Reprod Biol. 2011;158:28-32.

10. Vrouenraets FP, Roumen FJ, Dehing CJ, van den Akker ES, Aarts MJ, Scheve EJ. Bishop score and risk of cesarean delivery after induction of labor in nulliparous women. Obstet Gynecol. 2005;105:690-697.

11. van der Ven AJ, van Os MA, Kleinrouweler CE, et al. Midpregnancy Cervical Length in Nulliparous Women and its Association with Postterm Delivery and Intrapartum Cesarean Delivery. Am J Perinatol. 2016;33:40-46.

12. Seyb ST, Berka RJ, Socol ML, Dooley SL. Risk of cesarean delivery with elective induction of labor at term in nulliparous women. Obstet Gynecol. 1999;94:600-607.

13. Jozwiak M, Oude Rengerink K, Benthem M, et al. Foley catheter versus vaginal prostaglandin E2 gel for induction of labour at term (PROBAAT trial): an open-label, randomised controlled trial. Lancet. 2011;378:2095-2103.

14. Cromi A, Ghezzi F, Uccella S, Agosti M, Serati M, Marchitelli $G$, Bolis P. A randomized trial of preinduction cervical ripening: dinoprostone vaginal insert versus double-balloon catheter. Am J Obstet Gynecol. 2012;207:125.

15. Du YM, Zhu LY, Cui LN, Jin BH, Ou JL. Double-balloon catheter versus prostaglandin E2 for cervical ripening and labour induction: a systematic review and meta-analysis of randomised controlled trials. BJOG. 2017;124:891-899.

16. Shechter-Maor G, Haran G, Sadeh-Mestechkin D, Ganor-Paz Y, Fejgin MD, Biron-Shental T. Intra-vaginal prostaglandin E2 versus double-balloon catheter for labor induction in term oligohydramnios. J Perinatol. 2015;35:95-98. 
17. Mei-Dan E, Walfisch A, Valencia C, Hallak M. Making cervical ripening EASI: a prospective controlled comparison of single versus double balloon catheters. J Matern Fetal Neonatal Med. 2014;27:1765-1770.

18. Mei-Dan E, Walfisch A, Suarez-Easton S, Hallak M. Comparison of two mechanical devices for cervical ripening: a prospective quasi-randomized trial. J Matern Fetal Neonatal Med. 2012;25:723-727.

19. Bor P, Ledertoug S, Boie S, Knoblauch NO, Stornes I. Continuation versus discontinuation of oxytocin infusion during the active phase of labour: a randomized controlled trial. BJOG. 2016;123:129-135.

20. Rabie N, Magann E, Steelman S, Ounpraseuth S. Oligohydramnios in complicated and uncomplicated pregnancy: a systematic review and meta-analysis. Ultrasound Obstet Gynecol. 2017;49:442-449.

21. Maged AM, Deeb WS, Elbaradie S, Elzayat AR, Metwally AA, Hamed M, Shaker A. Comparison of local and intra venous dexamethasone on post operative pain and recovery after caeseream section. A randomized controlled trial. Taiwan J Obstet Gynecol. 2018;57:346-350.

22. Pevzner L, Powers BL, Rayburn WF, Rumney P, Wing DA. Effects of maternal obesity on duration and outcomes of prostaglandin cervical ripening and labor induction. Obstet Gynecol. 2009;114:1315-1321.
23. O'Dwyer V, O'Kelly S, Monaghan B, Rowan A, Farah N, Turner MJ. Maternal obesity and induction of labor. Acta Obstet Gynecol Scand. 2013;92:1414-1418.

24. Thorsell M, Lyrenäs S, Andolf E, Kaijser M. Induction of labor and the risk for emergency cesarean section in nulliparous and multiparous women. Acta Obstet Gynecol Scand. 2011;90:1094-1099.

25. Maged AM, El-Semary AM, Marie HM, et al. Effect of maternal obesity on labor induction in postdate pregnancy. Arch Gynecol Obstet. 2018;298:45-50.

26. Anabusi S, Mei-Dan E, Hallak M, Walfisch A. Mechanical labor induction in the obese population: a secondary analysis of a prospective randomized trial. Arch Gynecol Obstet. 2016;293:75-80.

27. Delaney S, Shaffer BL, Cheng YW, Vargas J, Sparks TN, Paul K, Caughey AB. Predictors of cesarean delivery in women undergoing labor induction with a Foley balloon. J Matern Fetal Neonatal Med. 2015;28:1000-1004.

28. Roos N, Sahlin L, Ekman-Ordeberg G, Kieler $H$, Stephansson O. Maternal risk factors for postterm pregnancy and cesarean delivery following labor induction. Acta Obstet Gynecol Scand. 2010;89:1003-1010. 